\title{
The Teaching of Science and Mathematics in English in Malaysia: Teachers' views on the implementation of two national initiatives
}

\author{
Nurul Sofia Ahmad Fuad, Nabilah Abdullah, Shireena Basree Abdul Rahman \\ Faculty of Education, \\ Universiti Teknologi MAR, Cawangan Selangor Kampus Puncak Alam, Selangor 42300, Malaysia \\ sofiafuad00@gmail.com nabil789@uitm.edu.my shire417@uitm.edu.my \\ Tel: 01111527221
}

\begin{abstract}
The Education Ministry has introduced two initiatives - English in the Teaching of Mathematics and Science (ETeMS) and Dual Language Programme (DLP) - to enhance mathematics and science learning using English as the medium of instruction. Numerous discontentment on ETeMS were reported but were not addressed before the DLP introduction in 2016. This qualitative research narrates teachers' views on both ETeMS and DLP, focusing on the coordinators' and implementers' challenges. Eleven mathematics and science school teachers have participated in this case study. Findings reveal that student-, resource- and teacher-related factors remained key reasons impeding effective learning of the two subjects.
\end{abstract}

Keywords: national policy; teaching and learning; science and mathematics; English.

eISSN: 2398-4287@ 2020. The Authors. Published for AMER ABRA cE-Bs by e-International Publishing House, Ltd., UK. This is an open access article under the CC BYNC-ND license (http://creativecommons.org/licenses/by-nc-nd/4.0). Peer-review under responsibility of AMER (Association of Malaysian Environment-Behaviour Researchers), ABRA (Association of Behavioural Researchers on Asians) and cE-Bs (Centre for Environment-Behaviour Studies), Faculty of Architecture, Planning \& Surveying, Universiti Teknologi MARA, Malaysia.

DOI: https://doi.org/10.21834/ebpj.v5iSI3.2554

\subsection{Introduction}

The Malaysian Education scenario has undergone vast changes in its attempt to sustain the aims and objectives stipulated in the Malaysian Education Blueprint (2013-2025). This can be seen through the implementation of various school-based initiatives such as Information and Communications Technology (ICT) integration through 1BestariNet, improving literacy via LINUS, and the enactment of the Malaysian Education Quality Standards (or SKPM). These to name a few, are aimed at providing better and more meaningful learning experiences for students. At present, education in Malaysia has its foundation deeply rooted in the National Education Blueprint that was first launched in September 2012. Among others, the blueprint focuses on empowering effective teachers to produce critical learners, and all these demands a certain degree of transformation in the education system. This blueprint was constructed based on the data gained through public discussions which involved views of about 50,000 stakeholders consisting of ministry officials, principals, teachers, students, parents, as well as members of the community (Tan, 2011). Among the many issues highlighted is the teaching of mathematics and science which resonates as being crucial and in need of serious attention.

For the longest time, mathematics and science have been taught using the National Language (Bahasa Malaysia) as its medium of instruction. Around the time when the national school curriculum went through a revision in the early 2000s, it was felt back then that for Malaysian graduates to be internationally competitive in the fields of Science and Technology, the two subjects are best taught in a

eISSN: 2398-4287@ 2020. The Authors. Published for AMER ABRA cE-Bs by e-International Publishing House, Ltd., UK. This is an open access article under the CC BYNC-ND license (http://creativecommons.org/licenses/by-nc-nd/4.0/). Peer-review under responsibility of AMER (Association of Malaysian Environment-Behaviour Researchers), ABRA (Association of Behavioural Researchers on Asians) and cE-Bs (Centre for Environment-Behaviour Studies), Faculty of Architecture, Planning \& Surveying, Universiti Teknologi MARA, Malaysia.

DOI: https://doi.org/10.21834/ebpj.v5iSI3.2554 
universal language that contributes to familiarity and ease of understanding of scientific terminologies and concepts, especially at the tertiary level. This has brought about the prompt implementation of English in the Teaching of Mathematics and Science (ETeMS) in 2002, highlighting the nation's seriousness in producing competent and globally competitive students in the forefront of science and technology. However, ETeMS was scrapped in 2011 due to public outcry and rejection as students failed to perform with English as the medium of instruction in the teaching of mathematics and science. Nonetheless, recently there was a move to revive the teaching of mathematics and science in English via the introduction of the Dual Language Program (DLP hereafter). This again has caused worry among different parties in dealing with the possibility that the nation may be facing similar issues and problems faced with ETeMS.

The issue of language as a contributing factor in the learning of mathematics and science has long been an area of interest. In the late 1980s, Crandall (1987) mentioned that the mastery of the language of mathematics and science becomes more complicated when students learn these subjects in the second language and this situation applies to the current Malaysian education setting. The ETeMS policy is said to affect a large number of students if it was continued and there was a huge tendency for students to fail in the subjects, while some who are weaker would eventually be left behind (Mohandas, 2015). Mohandas' statement is strongly agreed upon, as this was one of the initial reasons behind the retraction of ETeMS policy.

However, there are continuous demands from stakeholders for the implementation to be reinstated as some strongly stand with their views on the importance of learning both subjects in English. Former Deputy Education Minister, Datuk Mary Yap had mentioned that the shelving of the ETeMS policy is just temporary, as the ministry was not totally against it but was more focused on improving the proficiency of English among students and teachers first (The Star, 2013). The issue was taken on board to be revamped and further discussed among the officials. The Ministry of Education had later introduced a new effort named the Dual Language Programme (DLP), that was developed and under the MBMMBI (Upholding the Malay Language, Strengthening Command of English) where the program was first piloted in schools in 2016. Unlike the implementation of ETeMS in early 2002 as a nationwide policy, DLP was introduced in a smaller context, which is a program, but with similar objectives as the former policy.

Following the experiences during the implementation of ETeMS, the ministry and education officials have studied the expected impacts and consequences thus, DLP is believed to have gone through thorough discussion before it was implemented. The program started on a small scale, just with thirty pilot schools and it was not made compulsory to all schools in Malaysia. In ensuring that schools are ready to be involved in DLP, the ministry stated a guideline on the criteria that schools should observe before deciding to join the program. The criteria are as follows:

1. school must have sufficient teaching and learning materials.

2. the principal and teachers are prepared to implement DLP in school.

3. the school must have received demand and support from parents to implement the program.

4. the school's achievement in Bahasa Melayu for UPSR and SPM examinations must be higher than the subject's national average performance.

This research intends to look at the teachers' perceptions of the implementation of ETeMS and DLP, primarily focusing on the differences between the two. It also aims to understand teachers' concerns in their classroom teaching and learning process. The objectives are; to identify teachers' experiences and opinions on the two initiatives and to compare both initiatives based on the teachers' experiences. This study is significant as it helps in acknowledging the challenges teachers faced in their daily teaching routines and it is substantial, as it states relevant information for the ministry as well as other stakeholders, in helping them to understand and resolve the situations faced by DLP teachers.

\subsection{Literature Review}

Initial readings have revealed that the recent implementation of DLP has created issues among teachers as they consistently end up comparing DLP with ETeMS when sharing their insights. Besides difficulties in retrieving books and references, one of the key issues that need to be looked into is regarding the teachers' training. As we know, teachers' ability in policy implementation is one of the major keys (Pillay \& Thomas, 2004), and therefore, it is vital to ensure that teachers are well prepared to teach. Adding to that, teachers were said to be affected even more as they are not ready to be involved in the program and what more to teach the respective subjects in English (Nadiah \& Melor, 2019). Besides their ability and readiness to teach DLP subjects in English, things have become more challenging without formal training usually provided by the ministry. The absence of formal training in areas such as integrating content and language teaching has become a crucial factor in guiding classroom pedagogical practices (Tan, 2011). The tense increases even more when teachers faced difficulties in obtaining teaching materials. Teaching materials are crucial as teachers need suitable and sufficient materials to help them deliver well and enable them to achieve the objectives of the program (Bujang \& Mohd Hamzah, 2016 cited in Nadiah \& Melor, 2019). The issue regarding the shortage of textbooks and teaching references have surely affected teachers in delivering their job effectively. Similar issues mentioned have also been highlighted by parents and members of the public, besides just teachers in schools. Recently, the chairman of Parent Action Group of Education Malaysia (PAGE), Noor Azimah Abdul Rahim voiced that there is a need to improve on DLP implementation so that ETeMS can be reintroduced by the Prime Minister, Tun Dr. Mahathir Mohammad (The Star, 2018). 


\subsection{Methodology}

Adapting the case study research design, data in this qualitative study was gathered via face to face interview sessions, conducted in three urban and two rural secondary schools in Negeri Sembilan. By using the interview technique, it allows researchers to put the teachers' behavior in context and it will then develop the researcher's understanding of the teachers' action (Seidman, 2005). In this study, the list of schools was selected by the English Language Teaching Centre (ELTC) as schools selected were those that are involved in the DLP initiative. After obtaining approval from the State Education Department and the school principals, the researcher interviewed eleven DLP teachers from five secondary schools who have voluntarily agreed to be involved in the study. The semistructured interviews wereconducted in Bahasa Malaysia as respondents felt more comfortable to converse in the language and the recorded interviews were later transcribed verbatim. The complete transcriptions were then analyzed thoroughly and categorized according to codes and themes. It was then grouped into sections, evaluated, and summarized. Finally, the data is elaborated and discussed in paragraph writings. Despite the findings obtained, the data collected could not be generalized as the study was only conducted among selected DLP schools in Negeri Sembilan. Besides that, researchers were also unable to observe and compare students' achievements since schools have not had the results tabulated due to the early implementation of the DLP initiative.

\subsection{Findings}

a. Issues and concern encountered when implementing DLP

The issues and concerns that the teachers faced throughout the recent implementation of DLP are categorized according to two teacher categories, namely the coordinators and implementers. The difference between the two is that the former is mainly responsible for managing DLP in schools while the latter are the ones who execute; specifically involved with the teaching and learning in the classrooms. Summary of issues and concerns of the teachers by the said categories are as follows:

\begin{tabular}{|c|c|}
\hline Teacher Category & Issues and challenges \\
\hline Coordinator $(\mathrm{C}) \mathrm{N}=5$ & $\begin{array}{l}\text { Unclear guidelines or directives on aspects of DLP implementation from the state and federal education } \\
\text { offices } \\
\text { - on recognition of DLP school not based on criteria } \\
\text { - on DLP student selection } \\
\text { - on Buddy Support System } \\
\text { - on general communication } \\
\text { School readiness } \\
\text { - qualified teacher } \\
\text { - teaching and learning resources }\end{array}$ \\
\hline \multirow{3}{*}{ Implementor $(\mathrm{T}) \mathrm{N}=6$} & $\begin{array}{l}\text { Lack of Resources } \\
\quad \text { - textbooks, teaching modules }\end{array}$ \\
\hline & $\begin{array}{l}\text { Teachers } \\
\text { - untrained and lack of readiness to teach DLP classes } \\
\text { could teach well in mathematics and science subjects only if they previously learned the } \\
\text { subjects in English }\end{array}$ \\
\hline & $\begin{array}{l}\text { Students } \\
\text { - screened through UPSR results before enrolled in DLP classes } \\
\text { - low proficiency students who enrolled in DLP classes have difficulties in learning }\end{array}$ \\
\hline
\end{tabular}

b. Comparison between the challenges of DLP and those of ETeMS

Apart from the issues and concerns faced by the coordinators and teachers, the study also examines the differences in challenges faced during the implementation of DLP and ETeMS. The summary is as listed in the following table: 
Table 2: Comparing DLP and ETeMS

\begin{tabular}{|c|c|c|}
\hline Aspects/lssues & (2) & ETeMS \\
\hline Teacher & $\begin{array}{l}\text { - No formal training, just an online program to help } \\
\text { teachers in the subjects } \\
\text { - Buddy Support System conducted informally } \\
\text { - Lack of comprehensive briefing regarding the program } \\
\text { - No allowance } \\
\text { - Changes and uncertainties in language use for } \\
\text { examination }\end{array}$ & $\begin{array}{l}\text { - Training provided in centers } \\
\text { - Buddy Support System in place } \\
\text { - Special allowance as incentives } \\
\text { - } \text { Only English is allowed in the examination }\end{array}$ \\
\hline Student & $\begin{array}{l}\text { - Students' English language ability based on UPSR } \\
\text { - Readiness (proficiency - written and comprehension } \\
\text { skills) still low despite selection procedure }\end{array}$ & $\begin{array}{l}\text { - All students involved regardless of English language ability } \\
\text { - Overall readiness and proficiency low }\end{array}$ \\
\hline Content & - Difficulty relating to language, including terminology & - Difficulty relating to language, including terminology \\
\hline Resources & $\begin{array}{l}\text { - Designated textbooks not available } \\
\text { - Supporting materials and references not available }\end{array}$ & $\begin{array}{l}\text { - Designated textbooks and courseware were available } \\
\text { - Glossary and references were available }\end{array}$ \\
\hline Parents/guardian & $\begin{array}{l}\text { - Involved in the decision for the program implementation } \\
\text { - Can choose for their child not to be in the program }\end{array}$ & $\begin{array}{l}\text { - Not involved in any decision-making related to the policy } \\
\text { implementation } \\
\text { - Cannot choose as the policy is mandatory for all }\end{array}$ \\
\hline
\end{tabular}

\subsection{Discussion}

This section further discusses the issues mentioned in Table 1 with insertions of statements from the interviews conducted. Besides that, the information shared in Table 2 of the findings provides a substantial summary that helps readers to understand more about the differences between the two initiatives.

\section{Coordinators' issues and concern}

It was mentioned earlier that not all schools are DLP schools. Those categorized as DLP schools were either selected by the state education office or school's application upon meeting all the listed criteria. However, problems arise when there are exceptions to the stipulated ruling. For instance, one secondary school did not qualify to implement DLP, but it was required to run the program to cater to the needs of the secondary school pupils from nearby schools who were following the DLP program at the primary level.

Initially, the school was not selected but, the two primary schools nearby were DLP schools. So later on, they will send the children here. Hence, we had to (accept being DLP school), automatically we became one. (C1)

An undesirable setback of this situation is the readiness of the school to cater to DLP classes, especially with regards to qualified teachers and the availability of teaching and learning resources in English. Almost all coordinators, including those from schools that applied to be DLP certified, reported having difficulties to identify teachers to teach DLP classes. The main strategy employed by all schools in this study was to get teachers who have gone through ETeMS training to teach, besides randomly selecting teachers for the DLP classes. Both $\mathrm{C} 1$ and $\mathrm{C} 4$ voiced about this issue:

Maths and science teachers who have attended ETeMS courses before this are usually selected to teach DLP subjects, not the new teachers. (C1) We always try to get teachers who are good in English, have previously taught ETeMS to teach in DLP classes. (C4)

Another beleaguering issue confronted by the coordinators and teachers deals with the availability of teaching and learning (T\&L) resources in English. Unlike the complete resources in the form of a textbook, reference books, and courseware prepared before the implementation of ETeMS, the T\&L resources for DLP were reportedly unavailable as indicated by the following respondents. Lack of text and other resources have also been said to hamper both the teaching and learning processes:

No references books in English provided. Books, the textbooks, we use PPSMI books. (C2)

The current problem is, even form 3 students have not received any textbooks. (C4)

MOE said that they will be sending the resources (books and modules). But that did not happen. (C5)

Aside from uncertainties relating to DLP's school selection, another issue coordinators claimed to held confusion among them is regarding the selection of DLP students. All coordinators reported that schools made it compulsory for them to conduct a diagnostics test to screen the students for DLP classes. However, the test is not standardized and leads some schools to disregard the diagnostics test. Consequently, some students could not follow lessons in English and ended up performing badly in their examinations. 
Not only orders regarding school and pupil selection indistinct but the assessment aspect of DLP implementation is equally fuzzy. This specifically applies to questions being set up by schools instead of the District or State Education Office. Besides that, the inconsistent language instructions to be used in answering examination questions neither helped the pupils nor teachers. The frequent change in instruction from Malay to English and vice versa did not argue well for the pupils who either ended-up confused or encountered so many difficulties trying to answer the test as best as possible.

Following that, DLP implementation was also claimed to be uncertain with its continuation from lower to upper secondary level. As coordinators kept reminding teachers to give extra effort to ensure that students succeed in their DLP subjects, they encounter one of the biggest uncertainties when they could not get any confirmation regarding the continuation of DLP among form 4 students. Having this issue unresolved, teachers and parents are mostly contemplating and worry about the future of the DLP students. Some coordinators mentioned that their concern about this issue remains unanswered:

During the briefing session with PPD, they could not answer. (C1)

When I attended the briefing the other day, I was there to replace the headmistress. They said that they are not sure if DLP students will continue the program when they are in form 4. (C2)

The final issue discussed the existence of the school support system. Previously, the Buddy Support System - the pairing of an English teacher who serves as a mentor with one or more mathematics and science teachers to allow for better understanding, proficiency, and clarity in the classroom was one of the mechanisms used as a support system during ETeMS. However, this effort only exists informally during DLP without any specific standard operating procedure (SOP). Therefore, coordinators feel that it will be effective and of much help for the teachers if it is carried out properly during DLP.

Apart from matters concerning the management team, researchers have found out that issues concerning communication are vital in the current situation. Schools and teachers have received instructions by a circular from the Ministry of Education regarding the program implementation, which later trailed by meetings and briefings conducted by the State Education Department. From reviews done on the circular, it provides some general explanation about DLP. It explains the purpose of DLP implementation, qualifying criteria from DLP schools, and standard of the procedure (SOP) as a guideline in executing the program. However, other instructions and information that follows may have been missed out along the way, which has led to more problems and issues occurring in schools.

\section{Implementors' issues and concern}

Besides coordinators, there are issues to be looked into, among the implementors; the DLP teachers. The main issue mentioned by the implementors is regarding the insufficient amount of resources, specifically textbooks and other teaching materials. Implementors have been finding their ways and means to gain teaching resources to be used in teaching the DLP subjects.

As for now, we bought the books ourselves. Still, it is so difficult to find books. We only have PPSMI books. (T3)

No (official books). We bought ourselves. Some (references) we retrieved online. (T4)

In terms of reference books, especially for the first cohort, it is difficult for us to obtain any. We have to dig out the old books from PPSMI, the outdated books, and this year, since we don't have it we have to ask from other schools if they have it. (T6)

Other than resources, teachers' readiness is significant in ensuring the success of teaching and learning in the DLP classes. Some teachers, especially those who have not had any experience in teaching ETeMS feel uncomfortable and burdened when they are given the task due to the lack of ability to teach mathematics and science subjects in English.

However, some teachers who have learned mathematics and science subjects in English during their tertiary education sounded more positive and willing to accept the responsibility to teach in DLP classes. They might not be very proficient in English, but they are quite well-versed to teach their subjects using the language.

Those (terms), we learned them when we were in the university. We do not have any problem with the terms, because they do not change. But the students have to accept it, even though sometimes the pronunciation is wrong because we are not proficient in English subjects, but we learn the subjects (mathematics and science) in English. (T4)

In addition to teachers' readiness issues, the nature of students they received is also another concern among the teachers. Even though it was not stated in the circular, schools feel that they still need to screen the students based on their performance in UPSR to ensure that students who enrolled in form 1 DLP classes could "carry" the subjects and do well in their examination. Nonetheless, should the procedure follow as such, the number of students that could perform in DLP classrooms after a few months of learning, is still far too few, based on this study. Besides that, teachers sometimes have to allow students who do not meet the school requirements to be included in the program to ensure that they could have enough students to form the DLP class.

There are also cases where parents insist to get their child in the DLP classes despite knowing that their child is not ready to learn the subjects in English and this situation usually leads to poor performance among the students later on. However, even if students are not performing well, teachers could not do much about it since they do not have any rights to withdraw the students from the class unless both parents and the child themselves are willing to exit and attend the non DLP class. 


\subsection{Conclusion and Recommendations}

Researches conducted in other countries have shown that teachers teaching Mathematics and Science in a second language had confronted numerous problems (Jongsma and Jongsma, 2005) and this statement is agreed based on the data retrieved in this research. The data gained from the interview sessions conducted with 11 DLP teachers; 5 coordinators and 6 implementors have provided significant input regarding the issues and concerns in regards to DLP implementation. Both groups have highlighted differing concerns based on their job scope. They feel that clear guidelines and directions, effective communication, the sufficiency of teaching resources, and overall readiness to teach the subjects in English are issues to be resolved to ensure success in teaching and learning DLP subjects. Besides, comparisons made between DLP and ETeMS revealed that teachers have gone through different challenges in its implementation. Among the challenges, research has shown that teachers are trained only in approaches to teaching the content for their subjects (Lee, 2004). However, ETeMS's implementation previously has added a linguistic dimension to the classes. Therefore, teachers are given support to improve their proficiency in English as a part of its initiative (Tan, 2011). By having similar objectives, these initiatives are seen to have impacted teachers in several ways related to the teaching and learning process besides their motivational and emotional aspects. In conclusion, findings from this research have managed to highlight issues concerning the implementation of DLP and hopefully, relevant measures can be taken by those involved to improve its current state of being in ensuring a much improved and effective implementation of this nationwide initiative.

\section{Acknowledgments}

The authors would like to thank the Ministry of Education Malaysia particularly the ERPD unit for allowing us to explore the research area, the supportive Negeri Sembilan Education Department (JPNS), and the school principals as well as teachers who have willingly supported and participated in the research despite their tight schedule.

\section{References}

Crandall, J. (Ed.) (1987). ESL through Content Instruction: Mathematics, Science, Social Studies. Englewood Cliffs: Prentice-Hall Regents.

Jongsma, K., and Jongsma, G. (2005). Teaching Science and Mathematics in English in Grade 1 and 2 Classrooms in the UAE. International Journal of Learning, 12 (5), 225-236

Lee, M. (2004). Malaysian Teacher Education into the New Century. Reform of Teacher Education in the Asia Pacific in the New Millennium. Dordrecht: Kluwer Academic.

Mohandas, P. (2015). A Policy Analysis of the Delivery of Primary and Secondary School of Mathematics and Science in English. Education Research and Perspectives, An International Journal. Vol (42), 246-285.

Pillay \& Thomas (2004). A Nation on The Move: From Chalkface to Laptops. Paper presented at MICELT.

Nadiah, H.B \& Melor, M.Y. (2019). Teachers' Perceptions on the Implementation of Dual Language Programme (DLP) in Urban Schools. Asian Social Sciences, 15, 2431.

Seidman I., (2005). Interviewing as Qualitative Research. A Guide for Researchers in Education and the Social Sciences. Third Edition. Teachers College, Columbia University, New York, and London.

The Star (2013). Yap: Shelving PPSMI Only Temporary; Ministry to Focus on Improving English Language Proficiency First.

The Star Online (2018). Dr. M Will Bring Back the Glory Days. Retrieved on 25th May 2018 from the https://www.thestar.com.my/news/nation/2018/05/18/dr-m-willbring-back- the-glory-days-his-visionary-approach-towards-education-the-best-tonic-for-msia/

Tan, M. (2011). Mathematics and Science Teachers' Beliefs and Practices Regarding the Teaching of Language in Content Learning. Language Teaching Research, 15 (3), 325- 342. 